\title{
Hybrids of Two Closely Related Tropical Sea Urchins (Genus Echinometra): Evidence Against Postzygotic Isolating Mechanisms
}

\author{
M. AMINUR RAHMAN ${ }^{1}$, TSUYOSHI UEHARA ${ }^{1 *}$, AND JOHN S. PEARSE ${ }^{2}$ \\ ${ }^{1}$ Department of Marine and Environmental Sciences, Graduate School of Engineering and Science, \\ University of the Ryukyus, 1 Senbaru, Nishihara-cho, Okinawa 903-0213, Japan; and \\ ${ }^{2}$ Long Marine Laboratory, University of California, Santa Cruz, California 95064
}

\begin{abstract}
A series of cross-fertilization experiments were conducted with two unnamed, sympatric species of sea urchins in the Echinometra mathaei species complex, Echinometra sp. A (Ea) and Echinometra sp. C (Ec). Heterogametic fertilization success was high when eggs of Ec and sperm of Ea were involved, and low with eggs of Ea and sperm of Ec. Hybrids produced from crosses in either direction developed normally to sexually mature adults; Ea $\times$ Ea were largest in test size, followed by Ec (ova) $\times$ Ea (sperm), Ea (ova) $\times \mathrm{Ec}($ sperm), and Ec $\times \mathrm{Ec}$, respectively. Color patterns of the hybrids were closer to the maternal coloration, whereas other characters such as relative test dimensions and spine lengths, morphology of tubefoot and gonad spicules, and gamete sizes were intermediate. Fertilization rates in $F_{1}$ backcrosses were high, minimizing the possibility that hybrid infertility is a postzygotic mechanism of reproductive isolation. On the other hand, intensive surveys failed to find individuals with hybrid characteristics in the field, suggesting that natural hybridization between the two species is rare. Prezygotic isolating mechanisms, such as microhabitat separation and gamete incompatibility, at least between Ea eggs and Ec sperm, most likely maintain the genetic integrity of these two closely related species.
\end{abstract}

\section{Introduction}

Recent morphological, biochemical, ecological, and reproductive studies have revealed the presence of four sympatric biological species of sea urchins within the Echi-

Received 4 May 2000; accepted 15 December 2000.

* To whom correspondence should be addressed. E-mail ueharago@sci.u-ryukyu.ac.jp, or k988562@sci.u-ryukyu.ac.jp nometra mathaei, sensu lato, species complex at Okinawa, Japan. These species have been referred to as Echinometra species A, B, C, and D (e.g., Uehara and Shingaki, 1985; Uehara et al., 1990, 1991; Arakaki and Uehara, 1991; Matsuoka and Hatanaka, 1991; Nishihira et al., 1991; Palumbi and Metz, 1991; Palumbi, 1996, 1998; Aslan and Uehara, 1997; Palumbi et al., 1997). E. sp. B is now recognized as E. mathaei (de Blainville, 1825), sensu stricto, (Arakaki et al., 1998), while E. sp. D belongs in the E. oblonga (de Blainville, 1825) species complex, which may include at least three species (Arakaki and Uehara, 1999).

In sympatric echinoids like these species on Okinawa, interspecific reproductive isolation can result from different reproductive characteristics, such as timing and sites of spawning or gametic incompatibility (Lessios and Cunningham, 1990; Uehara et al., 1990; Palumbi and Metz, 1991; Metz et al., 1994; Palumbi, 1994, 1998; Vacquier et al., 1995; Aslan and Uehara, 1997; Lessios, 1998; McCartney et al., 2000). Of these factors, gamete incompatibility, preventing gametes of different species from fertilizing, may be particularly important for maintaining reproductive isolation of many animals (Dobzhansky et al., 1977), including echinoderms (Palumbi and Metz, 1991; Byrne and Anderson, 1994; Vacquier et al., 1995; Palumbi, 1998). On the other hand, postzygotic mechanisms such as the production of nonviable or infertile hybrids also could lead to and maintain reproductive isolation in various species (Coyne, 1992; Knowlton, 1993), including those of sea urchins (Chen and Baltzer, 1975; Lessios and Cunningham, 1990; Lessios, 1998; McCartney et al., 2000).

Of the four species on Okinawa, two, Ea and Eb, appear to be reproductively isolated by gametic incompatibility, 
Table 1

Echinometra sp. A and Echinometra sp. C: summary of characters relevant to identification and reproductive isolation

\begin{tabular}{|c|c|c|c|}
\hline Character & Echinometra sp. A & Echinometra sp. C & Sources* \\
\hline Habitat & Moat and tide pools & Burrows in reef margin & $1,2,6$ \\
\hline Bathymetric range & Intertidal, below mean low water & Intertidal, above mean low water & $1,2,6$ \\
\hline Salinity and thermotolerance & $\begin{array}{l}\text { Lower tolerance to sudden temperature and } \\
\text { salinity changes }\end{array}$ & $\begin{array}{l}\text { Higher tolerance to sudden temperature and } \\
\text { salinity changes }\end{array}$ & 4,5 \\
\hline Body size & Biggest among Okinawan Echinometra & Moderate among Okinawan Echinometra & 3 \\
\hline Wet weight $(\mathrm{g})$ & $50.8 \pm 12.8$ & $39.2 \pm 8.7$ & 7 \\
\hline Test length (mm) & $47.4 \pm 4.6$ & $43.3 \pm 0.1$ & 7 \\
\hline Spine length (mm) & $22.5 \pm 1.1$ & $16.6 \pm 0.9$ & 7 \\
\hline Spine color & $\begin{array}{l}\text { Entirely white to greenish, or brownish-black, } \\
\text { with white tip; distinct basal white ring }\end{array}$ & $\begin{array}{l}\text { Entirely green, brown, or greenish-brown, } \\
\text { without white tip; basal translucent, white ring. }\end{array}$ & 3 \\
\hline Tubefoot spicules & Bihamate (C-like) & Triradiate & 3 \\
\hline Gonadal spicules & Spindle shaped & Triradiate, curved triradiate, and bihamate & 3 \\
\hline Breeding season & April-December (max. around late September) & April-December (max. around late September) & 4,5 \\
\hline Egg diameter $(\mu \mathrm{m})$ & $66.9 \pm 1.3$ & $71.8 \pm 1.4$ & 7 \\
\hline Sperm head length $(\mu \mathrm{m})$ & $3.9 \pm 0.6$ & $6.4 \pm 0.7$ & 7 \\
\hline Jelly layer thickness $(\mu \mathrm{m})$ & $23.9 \pm 3.2$ & $18.1 \pm 3.5$ & 7 \\
\hline
\end{tabular}

* Data sources: 1, Tsuchiya and Nishihira (1984); 2, Tsuchiya and Nishihira (1985); 3, Uehara and Shingaki (1985); 4, Arakaki (1989); 5, Arakaki and Uehara (1991); 6, Nishihira et al. (1991); 7, this study; measurements from 25 adult individuals of each species examined for each character, mean \pm standard deviation.

because hybrids are not formed when their gametes are mixed (Uehara et al., 1990; Metz et al., 1994). On the other hand, two other species, Ec and Ed, readily form hybrids when their gametes are mixed, while all other combinations between the species show high asymmetries in fertilization (i.e., ova of one species are readily fertilized by sperm of another species, but not vice versa) (Uehara et al., 1990). Fertilization asymmetry also has been noted for the species of Echinometra in the Caribbean and eastern Pacific (Lessios and Cunningham, 1990). Although fertilization asymmetry indicates gamete incompatibility in one direction, there may be little or no gamete incompatibility in the other direction, allowing for ready hybridization. Because of such a possibility for hybridization, Lessios (1998) and McCartney et al. (2000) suggested that postzygotic mechanisms are important in maintaining the genetic integrity of these species in the field.

Sequence data of the cytochrome oxidase I gene indicates that the four species of Echinometra on Okinawa are of recent origin, considerably less than 3 million years old (Palumbi, 1996), and similar to the time of divergence between the Atlantic and eastern Pacific species of Echinometra (McCartney et al., 2000). Moreover, allozyme evidence indicates that among the four species on Okinawa, $\mathrm{Ea}$ and Ec are the most closely related to each other, while $\mathrm{Ea}$ and Ed are the most divergent (Matsuoka and Hatanaka, 1991). Experimental hybridization and rearing experiments by Aslan and Uehara (1997) reported that Ed ova were readily fertilized by Ea sperm, but Ea ova were much less able to be fertilized by Ed sperm. Hybrids resulting from crosses in both directions developed normally into fertile adults, and Aslan and Uehara (1997) suggested that introgression between Ea and Ed was probably minimized by prezygotic mechanisms, particularly separation of their respective microhabitats. Rahman et al. (2000) also reported asymmetrical fertilization in $\mathrm{Ea} \times \mathrm{Ec}$ crosses, with Ec ova being more readily fertilized by Ea sperm than Ea ova were fertilized by Ec sperm. Moreover, they found that the viability and growth of Ec (ova) $\times \mathrm{Ea}$ (sperm) hybrids was similar to that of conspecifics, while that of Ea (ova) $\times$ Ec (sperm) hybrids was significantly lower. We report here further details of hybrids between these two species. In spite of their close relationship, individuals of Ea and Ec can be readily distinguished from each other by differences in adult morphology, as well as microhabitat preference (Table 1). On the other hand, their breeding seasons overlap extensively (Arakaki and Uehara, 1991) and because of the proximity of their microhabitats (Nishihira et al., 1991), they are likely to have opportunities to hybridize in the field.

\section{Materials and Methods}

Mature adults of Ea (identified by their brownish dark test and white-tipped spines), and Ec (greenish test, spines without white tips, but with white basal ring distinguishing it from Eb) (Uehara, 1990; Arakaki et al., 1998) were collected from the Sunabe coast of Okinawa Island $\left(26^{\circ} 07^{\prime} \mathrm{N}\right.$; $127^{\circ} 46^{\prime}$ E) at low tide within their natural breeding season from early May to late October, 1996 and 1997. Specimens were immediately transported to the laboratory, where they were maintained in closed aquaria until spawned. Crossfertilization of the two species of Echinometra was con- 


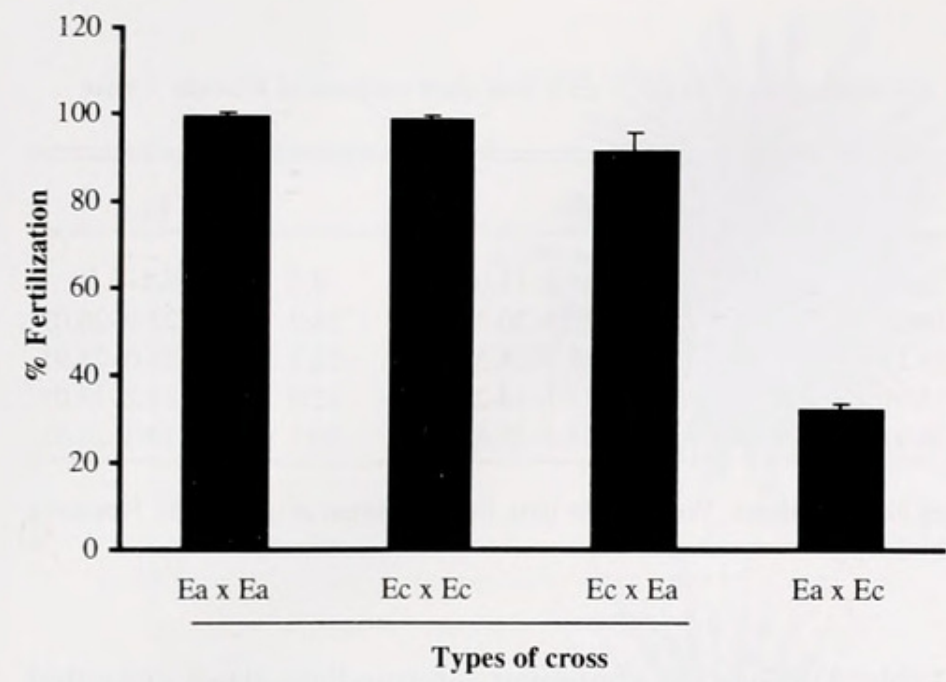

Figure 1. Mean percentage of eggs fertilized in conspecific and heterospecific crosses of Echinometra sp. A (Ea) and Echinometra sp. C (Ec); maternal species named first. Calculated from number of embryos in the 2 to 4 -cell stage counted in 100 eggs 1.5 hours after gamete mixing. A total of 13 replicate crosses were done using gametes from new individuals each time; error bars indicate 1 standard deviation. Fertilization rate of $\mathrm{Ea} \times \mathrm{Ec}$ significantly different from those of $\mathrm{Ea} \times \mathrm{Ea}, \mathrm{Ec} \times \mathrm{Ec}$, and $\mathrm{Ec} \times \mathrm{Ea}$ (ANOVA, $P<0.01$ ), as indicated by the horizontal bar. Data from Rahman et al. (2000).

ducted using all possible combinations of ova and sperm at room temperatures $\left(26-28^{\circ} \mathrm{C}\right)$ (Rahman et al., 2000). For consistency, when referring to heterospecific crosses, the maternal species is named first. As found earlier by Uehara et al. (1990), fertilization was high for the conspecific and Ec $\times$ Ea crosses, but significantly lower for the Ea $\times$ Ec crosses (Fig. 1). The juveniles produced from these crosses were used in the work reported here.

The embryos and larvae were reared through metamorphosis, as described by Rahman et al. (2000). Larval survival was $68 \%-73 \%$ for the conspecific and $\mathrm{Ec} \times \mathrm{Ea}$ crosses, and $50 \%$ for the Ea $\times$ Ec crosses. Larval body form and development of both conspecific controls and reciprocal hybrids were similar to each other, and no particular abnormalities were observed. After 20-24 days, larvae were placed in small $(25 \times 20 \times 10 \mathrm{~cm})$ aquaria with aerated, filtered seawater, and pieces of coralline algal skeletons were added to induce settlement and metamorphosis. Metamorphosis rate was high $(84 \%-89 \%)$ and not significantly different for the conspecific and Ec $\times$ Ea larvae, and lower $(67 \%)$ for the $\mathrm{Ea} \times \mathrm{Ec}$ hybrids (Rahman et al., 2000). Seawater was partially changed once a week with fresh, filtered seawater, and coralline-algal-encrusted pieces of coral skeletons were provided as food. By 3 months, $65 \%-$ $69 \%$ of the conspecific and $\mathrm{Ec} \times$ Ea juveniles, and $57 \%$ of the Ec $\times$ Ea juveniles remained; they were all $6.0-7.0 \mathrm{~mm}$ in test diameter.

The cultures were continued for one year, by which time the animals were sexually mature; survival at one year was $78 \%-84 \%$ for the conspecifics and Ec $\times$ Ea hybrids, and
$70 \%$ for the Ea $\times$ Ec hybrids (Rahman et al., 2000). Then they were spawned, and their gametes were used for reciprocal back crosses to determine fertility among both hybrids and conspecifics. After the animals were spawned, data on animal weight, test dimensions, spine lengths, spicule characteristics, body and spine coloration, gamete sizes, and other specific characters of all the animals were recorded and compared among the treatments. The tests of echinoids in the family Echinometridae are oblong, so both length and width, as well as height, were measured. Spicule types in both the tube feet and gonads were counted in 10 replicate samples from 20 different individuals of each cross (80 animals; 800 counts). Gametes were measured using a phase contrast microscope following Amy (1983) (eggs at $400 \times$ in a slide well; sperm at $1000 \times$ on a flat slide).

Percentages were arcsine transformed to normalize the data and reduce heterogeneity in variances. Homogeneity of variances was analyzed by a Bartlett test (Bartlett, 1937); when variances were not significantly heterogeneous and showed no major departure from normality, a one-way analysis of variance (ANOVA) was done, followed by Duncan's multiple range test (Duncan, 1955). The level for statistical significance was set at 0.05 . Untransformed values are presented in the tables and figures.

To examine the occurrence of hybridization between Ea and Ec in the field, searches for specimens with hybrid morphology were conducted along the Sunabe coast of Okinawa and the coast of Sesoko Island, where both species occur close together (within 1-2 m) in adjacent, interdigitating microhabitats.

\section{Results}

\section{Comparisons of laboratory-reared adult Echinometra $s p$.}

\section{$A$, Echinometra sp. $C$, and their reciprocal hybrids}

Test length of animals 1 year after metamorphosis (Table 2) was less than for field-collected animals (Table 1), which were probably several years old. On the other hand, spine lengths of the experimental animals were greater than those of the field-collected animals, which live in rock depressions under turbulent conditions and experience considerable spine-tip abrasion.

Mean values for wet weight, test length, width, height, and spine length were greatest in $\mathrm{Ea} \times \mathrm{Ea}$ progeny and smallest in $\mathrm{Ec} \times \mathrm{Ec}$ progeny (Table 2). All these parameters were significantly different between $\mathrm{Ea} \times \mathrm{Ea}$ and $\mathrm{Ec} \times \mathrm{Ec}$, and between each of these and the hybrids. On the other hand, there were no significant differences $(P>0.05)$ between Ea $\times \mathrm{Ec}$ and $\mathrm{Ec} \times \mathrm{Ea}$. Measurements in both of the reciprocal hybrids were closer to those of $\mathrm{Ea} \times \mathrm{Ea}$ than to Ec $\times$ Ec. These measurements mirror the different growth rates found for these animals by Rahman et al. (2000).

The aboral body coloration differed between conspecifics and hybrids (Fig. 2, upper). In Ea $\times$ Ea specimens, test 
Table 2

Weight, test size, and spine length comparison of Echinometra sp. A (Ea $\times$ Ea), Echinometra $s p . C$ (Ec $\times$ Ec), and their reciprocal hybrids 1 year after metamorphosis

\begin{tabular}{|c|c|c|c|c|}
\hline Character & $\mathrm{Ea} \times \mathrm{Ea}$ & $\mathrm{Ea} \times \mathrm{Ec}$ & $\mathrm{Ec} \times \mathrm{Ea}$ & $\mathrm{Ec} \times \mathrm{Ec}$ \\
\hline Wet weight $(\mathrm{gm})$ & $14.7 \pm 0.7^{a}(14.6-14.8)$ & $13.6 \pm 0.2^{b}(13.6-13.7)$ & $13.9 \pm 0.5^{b}(13.8-14.0)$ & $9.2 \pm 0.5^{c}(9.1-9.3)$ \\
\hline Test length ( $\mathrm{mm})$ & $29.4 \pm 0.8^{\mathrm{a} *}(28.2-31.0)$ & $28.4 \pm 0.9^{\mathrm{b}}(27.0-30.0)$ & $28.7 \pm 0.8^{b}(27.5-30.5)$ & $24.2 \pm 1.1^{\mathrm{c}}(23.0-26.0)$ \\
\hline Test width (mm) & $27.3 \pm 0.8^{a}(26.1-29.0)$ & $26.3 \pm 0.9^{b}(25.0-28.1)$ & $26.5 \pm 0.8^{b}(25.3-28.5)$ & $22.2 \pm 1.0^{c}(21.0-23.9)$ \\
\hline Test height $(\mathrm{mm})$ & $14.2 \pm 0.4^{a}(13.6-15.0)$ & $13.5 \pm 0.4^{b}(12.8-13.9)$ & $13.6 \pm 0.3^{b}(13.1-14.2)$ & $12.0 \pm 0.5^{\mathrm{c}}(11.2-13.0)$ \\
\hline Spine length $(\mathrm{mm})$ & $26.8 \pm 1.0^{\mathrm{a}}(24.4-28.2)$ & $23.4 \pm 0.7^{b}(22.3-24.9)$ & $24.3 \pm 0.6^{\mathrm{b}}(23.4-25.5)$ & $20.7 \pm 0.7^{c}(19.3-21.9)$ \\
\hline
\end{tabular}

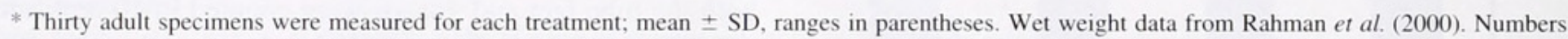
in the same row having the same superscripts are not significantly different $(P>0.05)$.

color was dark brownish, and each spine had a white tip and a translucent white ring at its base. Ec $\times$ Ec specimens were uniformly greenish, and each spine was uniformly colored except for a faded basal white ring. Ea $\times$ Ec hybrids were more similar to $\mathrm{Ea} \times \mathrm{Ea}$ conspecifics, having dark brownish tests and white-tipped spines with a translucent white, basal ring. On the other hand, Ec $\times$ Ea hybrids were more similar to Ec $\times$ Ec conspecifics; the tests were uniformly deep greenish, and the spines had barely detectable white tips and basal white rings.

Orally (Fig. 2, lower), Ea $\times$ Ea conspecifics had whitetipped spines around the mouth and brownish dark tests, whereas Ec $\times$ Ec conspecifics had yellowish green spines around the mouth and a greenish test color. Ea $\times$ Ec hybrids were more similar to $\mathrm{Ea} \times \mathrm{Ea}$, whereas $\mathrm{Ec} \times \mathrm{Ea}$ hybrids were more similar to $\mathrm{Ec} \times \mathrm{Ec}$; that is, hybrid coloration was most similar to maternal coloration.

Tubefoot spicules in Ea $\times$ Ea were always bihamate (C-shaped), whereas those in Ec $\times$ Ec were always triradiate (Fig. 3). Tubefoot spicules of Ea $\times$ Ec hybrids were bihamate $(58 \%)$, bihamate-like $(17 \%)$, triradiate-bihamate $(20 \%)$, and triradiate $(5 \%)$, whereas those of Ec $\times$ Ea were bihamate $(32 \%)$, bihamate-like $(12 \%)$, triradiate-bihamate $(44 \%)$, and triradiate (13\%). Therefore, the tubefoot spicule morphologies of the hybrids were intermediate and tended toward maternal affinities.

There was little intraspecific variation in gonadal spicule morphology (Fig. 4). The spicules in Ea gonads were almost all spindle-shaped (98\%; other spicules seen: bihamate, $<1 \%$; irregular, $1 \%$; no triradiates were found). In contrast, those in Ec gonads were nearly all triradiate (94\%; other spicules seen: spindle, $5 \%$; bihamate, $1 \%$ ). Gonads in both $\mathrm{Ea} \times \mathrm{Ec}$ and $\mathrm{Ec} \times \mathrm{Ea}$ had high proportions of spindleshaped spicules ( $62 \%$ and $46 \%$, respectively), with spindlelike $(16 \%$ and $11 \%)$, triradiate-spindle $(13 \%$ and $25 \%)$, triradiate $(7 \%$ and $15 \%)$, bihamate ( $1 \%$ in both), and irregular (1\% in both) spicules in smaller proportions.

Gamete sizes of conspecific and hybrid individuals were different. Egg diameters of $\mathrm{Ea} \times \mathrm{Ea}$ were smallest among the four treatments, whereas the Ec $\times$ Ec eggs were largest
(Table 3). Hybrids contained intermediate-sized eggs that were significantly different from the eggs of either of the conspecifics. The sizes of sperm heads were also smallest in $\mathrm{Ea} \times \mathrm{Ea}$, and were significantly different among all the crosses, including between the hybrids.

\section{Existence of natural hybrids}

The characteristics of reproductively mature hybrids are summarized in Table 4. Two hundred individuals with coloration more-or-less intermediate between the two species were collected from the field. However, detailed comparisons of spicule shapes and gamete sizes revealed that none actually had character combinations common to the experimentally obtained hybrids; that is, all could be assigned to either Ea or Ec on the basis of both spicule shapes and gamete sizes.

Similarly, Aslan and Uehara (1997) did not find any natural hybrids between Ea and Ed in the field, even though they were able to rear hybrids of these species in the laboratory.

\section{Backcrosses}

There was no indication that the hybrids were any less fertile than either of their conspecific half-siblings (Table 5). Eggs from both $\mathrm{Ea} \times \mathrm{Ec}$ and $\mathrm{Ec} \times \mathrm{Ea}$ yielded higher percentages of fertilization with Ea $\times$ Ea sperm $(93 \%$ and $98 \%)$, than with Ec $\times$ Ec sperm $(82.2 \%$ and $89.2 \%)$, similar to the findings with the parental crosses in which Ea sperm more readily fertilized Ec eggs than Ec sperm fertilized Ea eggs (Fig. 1). Moreover, backcrosses by sperm from males of $\mathrm{Ea} \times \mathrm{Ec}$ and $\mathrm{Ec} \times \mathrm{Ea}$ yielded higher percentages of fertilization with Ec $\times$ Ec ova $(99.3 \%$ and $99.7 \%)$ than with Ea $\times$ Ea ova $(84 \%$ and $86.5 \%)$; Ea ova appear to be more discriminating than Ec ova. The higher fertilization rates between the same types of hybrids versus the different types of hybrids (99.5\% and $99 \%$ versus $95 \%$ and $86 \%$ ) indicate the presence of a complex sorting of gamete compatibility genes. 

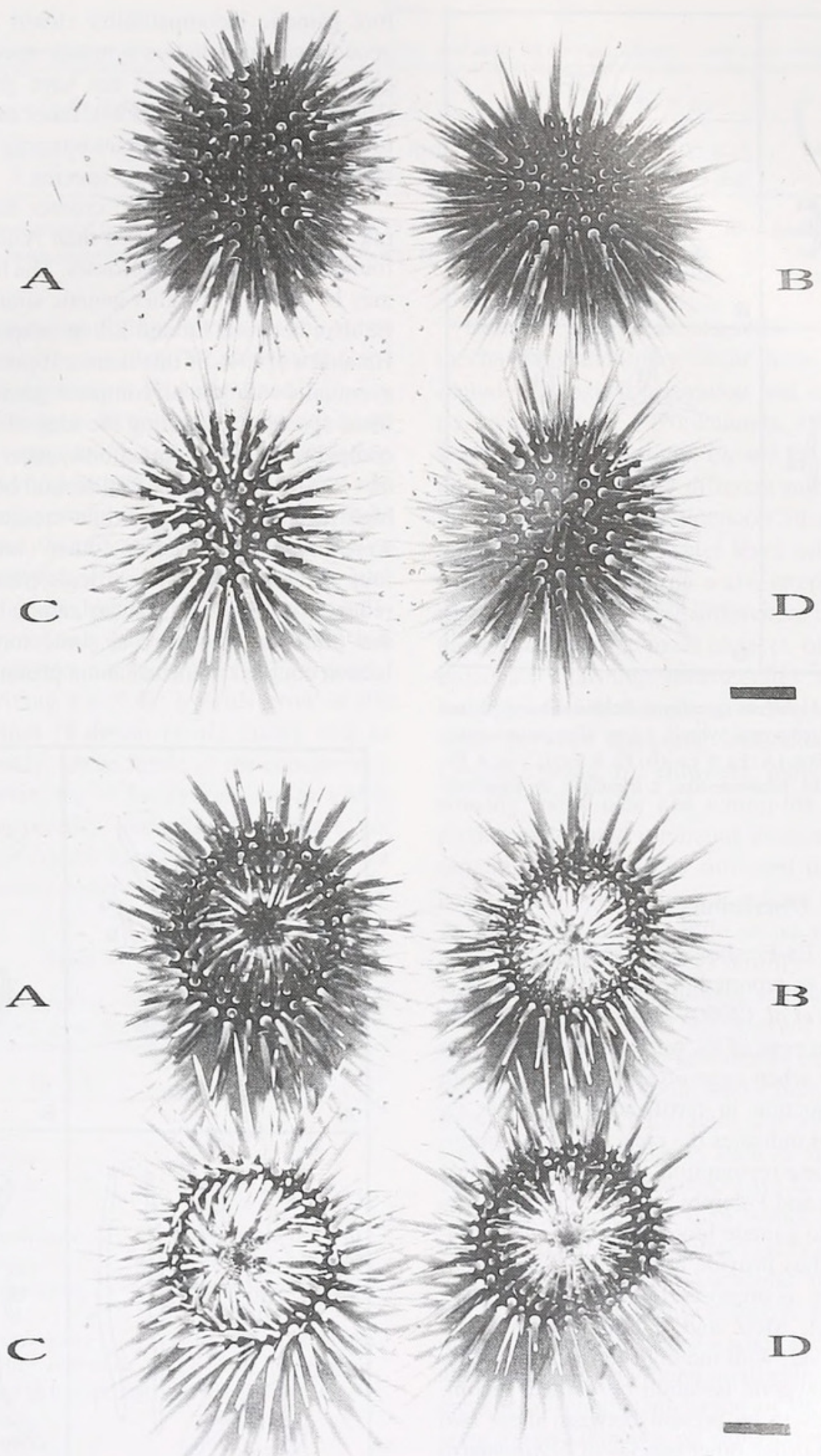

Figure 2. Aboral (upper) and oral (lower) color patterns of Echinometra sp. A and E. sp. C, and their reciprocal hybrids, 1 year after metamorphosis; maternal species named first. (A) Ea $\times$ Ea; (B) Ec $\times$ Ec; (C) $\mathrm{Ea} \times \mathrm{Ec}$; (D) $\mathrm{Ec} \times \mathrm{Ea}$. 


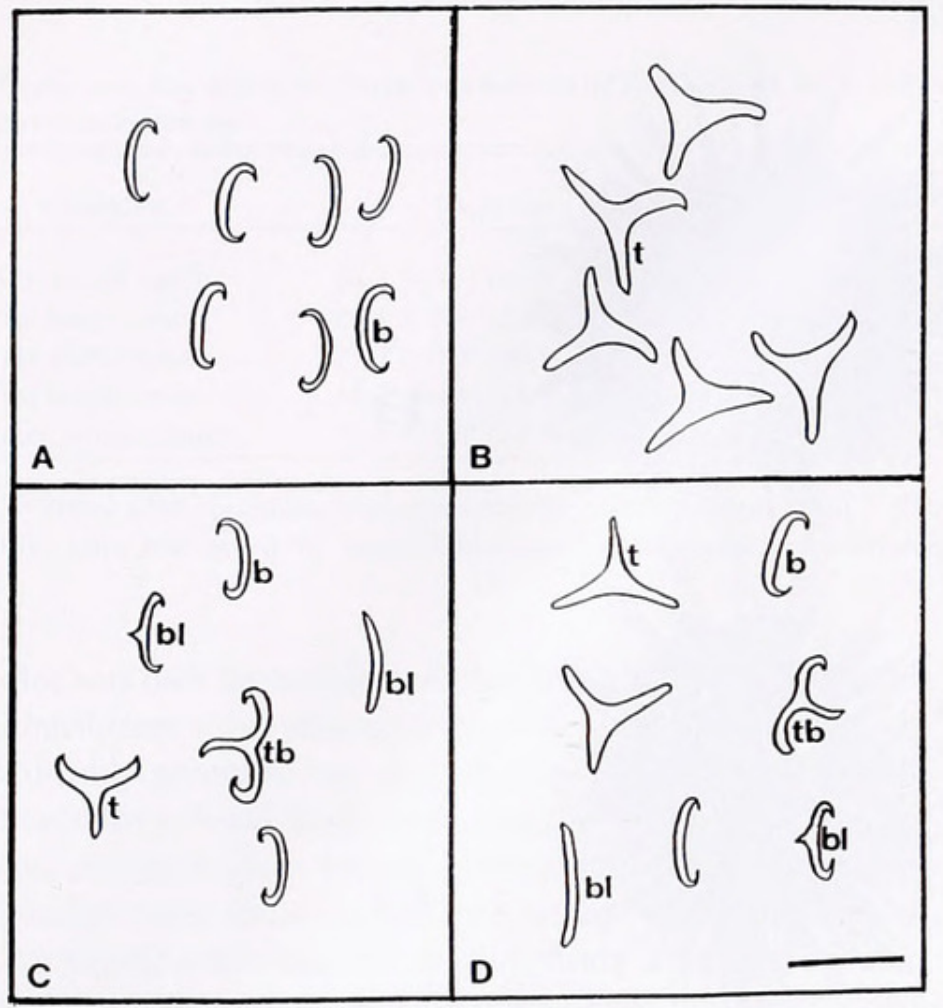

Figure 3. Morphology of tubefoot spicules of Echinometra sp. A and Echinometra sp. C and their reciprocal hybrids, 1 year after metamorphosis; maternal species named first. (A) $\mathrm{Ea} \times \mathrm{Ea}$; (B) $\mathrm{Ec} \times \mathrm{Ec}$; (C) $\mathrm{Ea} \times \mathrm{Ec}$; (D) Ec $\times$ Ea. b, bihamate; bl, bihamate-like; t, triradiate; tb, triradiatebihamate. Scale bar, $50 \mu \mathrm{m}$.

\section{Discussion}

The crosses between Ea-Ec showed a distinct asymmetry in fertilization success, as reported previously by Uehara $e t$ al. (1990) and Rahman et al. (2000). Heterogamic fertilization rate was high when eggs of Ec were mixed with sperm of Ea, but much lower when eggs of Ea were mixed with sperm of Ec. The reduction in fertilization with the Ea egg $\times$ Ec sperm crosses indicates the presence of a proteinbinding system for gamete recognition, as reported by Metz et al. (1994), and Metz and Palumbi (1996). Such a system might eventually lead to gamete incompatibility and reproductive isolation, and thus provide a mechanism for maintaining species integrity, as proposed by Metz et al. (1994), Vacquier et al. (1995), Metz and Palumbi (1996), and Palumbi (1998). However, with the high fertilization of Ec eggs by Ea sperm, prezygotic isolation by gamete incompatibility hardly appears to be present between these two species, or among most of the other species of Echinometra on Okinawa, most of which, like the two sympatric species of Caribbean Echinometra, also show high asymmetry in fertilization among hybrid crosses (Uehara et al., 1990; Lessios and Cunningham, 1990). Consequently, it seems unlikely that gamete incompatibility, by itself, provides a mechanism for reproductive isolation in Echinometra. Reproductive isolation and speciation apparently occurred be- fore gametic incompatibility closed off the possibility of gene flow, and as in two sympatic species of asteroids in the genus Patiriella that do not have gamete incompatibility (Byrne and Anderson, 1994), other mechanisms need to be found to explain how species integrity is maintained in these closely related, interfertile species.

Furthermore, the Ea-Ec crosses had higher fertilization rates in the $F_{1}$ backcrosses than Aslan and Uehara (1997) found for Ea-Ed $F_{1}$ backcrosses. The higher fertilization rate may be due to the higher genetic similarity between Ea and Ec than between Ea and Ed, as proposed by Matsuoka and Hatanaka (1991). If this is true, it provides evidence for the eventual evolution of complete gamete incompatibility in these species. Supporting the idea of a transition of gamete compatibility to incompatibility after speciation, Uehara $e t$ al. (1990) reported that fertilization between Ec and Ed was high in both directions, while crosses between $\mathrm{Ea}$ and $\mathrm{Eb}$ were completely infertile; other combinations among the four species were asymmetrical. Whether these differences reflect evolutionary distances among the species, or indicate that other factors - such as some sort of reinforcement selection coupled to microhabitat proximity - are involved, or

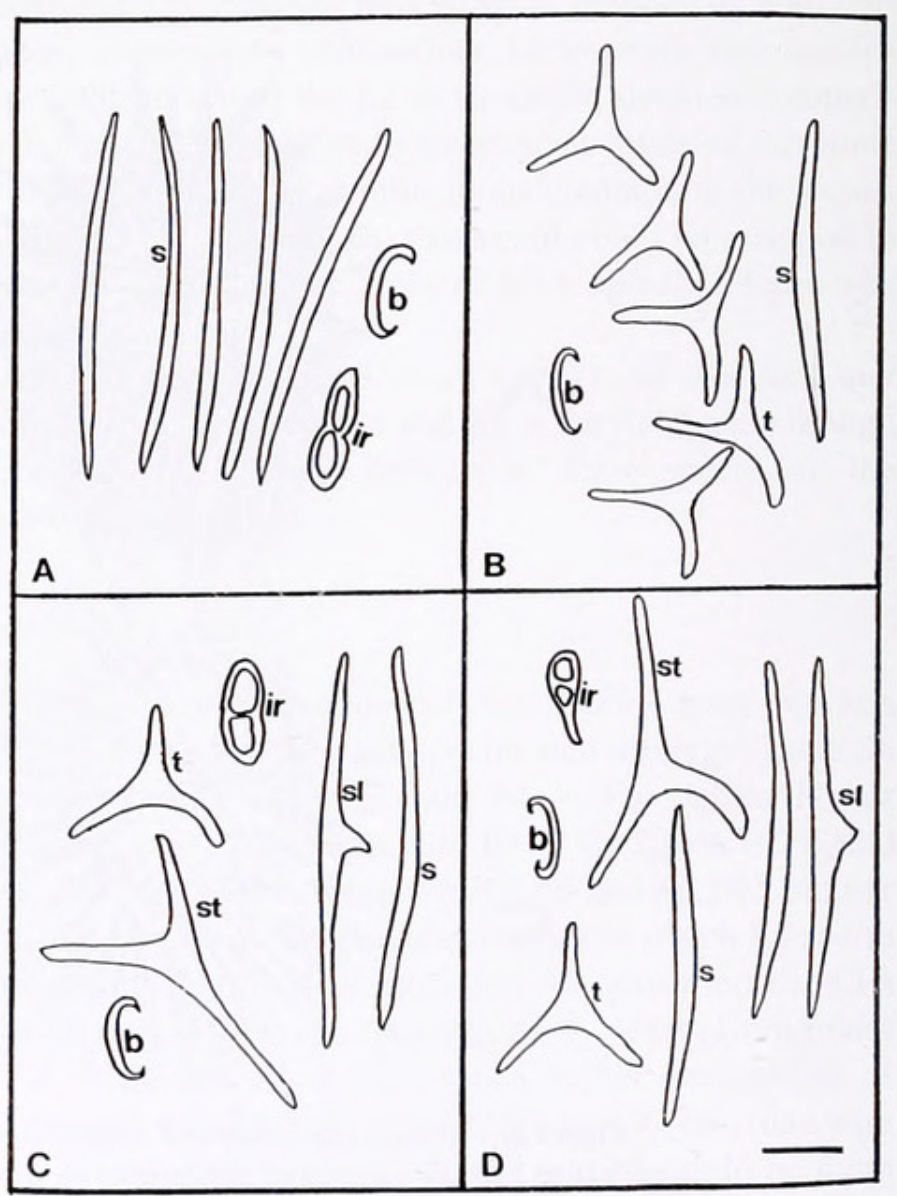

Figure 4. Morphology of gonadal spicules of Echinometra sp. A and Echinometra sp. C and their reciprocal hybrids, 1 year after metamorphosis; maternal species named first. (A) Ea $\times \mathrm{Ea}$; (B) Ec $\times$ Ec; (C) Ea $\times$ Ec; (D) Ec $\times$ Ea. b, bihamate, ir, irregular, s, spindle; sl, spindle-like; st, spindle-triradiate; t, triradiate. Scale bar, $100 \mu \mathrm{m}$. 
Table 3

Gamete sizes of Echinometra sp. A $(E a \times E a)$, Echinometra sp. $C(E c \times E c)$, and their reciprocal hybrids 1 year after metamorphosis

\begin{tabular}{|c|c|c|c|c|}
\hline Measurement & $\mathrm{Ea} \times \mathrm{Ea}$ & $\mathrm{Ea} \times \mathrm{Ec}$ & $\mathrm{Ec} \times \mathrm{Ea}$ & $\mathrm{Ec} \times \mathrm{Ec}$ \\
\hline Egg diameter & $66.9 \pm 1.0^{\mathrm{a} *}(65.0-67.5)$ & $71.0 \pm 1.2^{\mathrm{b}}(70.0-73.8)$ & $70.2 \pm 1.1^{b}(67.5-72.5)$ & $72.6 \pm 1.3^{c}(71.3-75.0)$ \\
\hline Sperm head length & $4.1 \pm 0.5^{\mathrm{a}}(3.1-5.0)$ & $5.7 \pm 0.7^{b}(4.3-6.8)$ & $5.2 \pm 0.8^{c}(4.3-6.8)$ & $6.5 \pm 0.8^{d}(5.0-7.4)$ \\
\hline
\end{tabular}

* Twenty individuals were examined from each cross with 25 eggs and 25 sperm from each individual; mean \pm SD in $\mu \mathrm{m}$, ranges in parentheses. Figures in the same row having the same superscripts are not significantly different $(P<0.05)$.

suggest that gametic incompatibility in one or the other species "simply happened by accident" (Lessios and Cunningham, 1990, p. 938) remains to be determined.

The successful culturing of hybrids to fertile adults in laboratory conditions suggests that postzygotic isolating mechanisms, such as hybrid inviability or sterility, are not involved in maintaining species integrity. However, Rahman et al. (2000) found that Ea $\times$ Ec hybrids had lower larval survival, metamorphosis success, and juvenile survival than either $\mathrm{Ec} \times \mathrm{Ea}$ hybrids or conspecific halfsiblings. Consequently, not only gamete incompatibility but postzygotic fitness parameters act against $\mathrm{Ea} \times \mathrm{Ec}$ hybrids. Nevertheless, the surviving Ea $\times \mathrm{Ec}$ hybrids grow at the same rate as conspecifics (Rahman et al., 2000), and as shown in the present study, are as fertile as the conspecifics in backcrosses. Moreover, Ec $\times$ Ea hybrids are as viable and fertile as the conspecifics, indicating that there are neither gametic nor postzygotic blocks to introgression for at least half of the possible hybrid events.

Table 4

Characterization of hybrids produced experimentally through cross fertilization between Echinometra sp. $A(E a)$ and Echinometra sp. $C(E c)$

\begin{tabular}{|c|c|c|}
\hline Distinctive features & $\mathrm{Ea} \times \mathrm{Ec}$ & $\mathrm{Ec} \times \mathrm{Ea}$ \\
\hline \multicolumn{3}{|l|}{ Body color } \\
\hline a. Oral & Ea-like & Ec-like \\
\hline b. Aboral & Ea-like & Ec-like \\
\hline \multicolumn{3}{|l|}{ Test sizes } \\
\hline a. Length & Intermediate & Intermediate or Ea-like \\
\hline b. Width & Intermediate & Intermediate or Ea-like \\
\hline c. Height & Intermediate & Intermediate or Ea-like \\
\hline \multicolumn{3}{|l|}{ Spines } \\
\hline a. Length & Intermediate & Intermediate or Ea-like \\
\hline b. Color & $\begin{array}{l}\text { Ea-like with white } \\
\text { tip or intermediate }\end{array}$ & $\begin{array}{l}\text { Ec-like or intermediate } \\
\text { with faint white } \\
\text { spine tip }\end{array}$ \\
\hline c. Milled ring color & Ea-like & Ea-like \\
\hline \multicolumn{3}{|l|}{ Spicules } \\
\hline a. Tubefoot & $\begin{array}{l}\text { Intermediate and } \\
\text { Ea-like }\end{array}$ & Intermediate and Ec-like \\
\hline b. Gonad & $\begin{array}{l}\text { Intermediate and } \\
\text { Ea-like }\end{array}$ & Intermediate and Ea-like \\
\hline \multicolumn{3}{|l|}{ Gametes } \\
\hline a. Sperm sizes/form & Intermediate & Intermediate \\
\hline b. Egg sizes & Intermediate & Intermediate \\
\hline
\end{tabular}

Besides gamete incompatibility, potential prezygotic mechanisms that may occur between these two species include ecological separation and asynchronous reproductive cycles (Mayr, 1970; Palumbi, 1994). The two species of sea urchins in this study, Ea and Ec, live relatively close to each other but occupy different microhabitats; Ea inhabits the calmer moat and tidepools of the reef-flat, generally below the mean low water level, whereas Ec inhabits burrows or crevices in the wave-swept intertidal of the reef margin (Table 1). These differences in microhabitats may be enough to prevent most chances of cross fertilization. In broadcast spawning invertebrates such as echinoids, for example, fertilization success drops dramatically with distance between spawning individuals (Pennington, 1985; Levitan, 1998a, b). However, individuals of Ea are occasionally found near and within the reef margin where Ec predominates, and it remains unclear, whether microhabitat separation, by itself, is sufficient to prevent introgression between the two species, or at least through Ec ova and Ea sperm where there is little or no gamete incompatibility, hybrid viability, or hybrid fertility.

In addition to the problem of being separated enough in adjacent microhabitat to prevent gamete mixing after spawning, there is the problem of maintaining microhabitat differentiation that could assure reproductive isolation. This problem is especially acute for species with long-lived, widely dispersing larvae, such as species of Echinometra. The different larvae would have to have exquisite settling cues that assured that they would be established in their exact microhabitats or suffer highly selective postsettlement mortality outside their particular microhabitats. There is little evidence of highly selective habitat selection in sea urchin larvae (Pearse and Cameron, 1991). Indeed, Rahman and Uehara (2001) found no discrimination in settling preferences by competent larvae of the four species of Echinometra on Okinawa; all showed settlement rates of $86 \%$ $89 \%$ on coralline red algae, and much lower rates on other algae. The mechanism resulting in and maintaining microhabitat differentiation among broadcast spawning species such as those of Echinometra in the tropical west Pacific remain unknown and unexplored.

Echinoid sperm are active for only a short time after spawning, much less than an hour in temperate species 
Table 5

Percentage of eggs fertilized in backcrosses among laboratory-reared $F_{/}$generation of conspecifics and hybrids of Echinometra sp. A (Ea) and Echinometra sp. $C(E c)$

Eggs from

\begin{tabular}{|c|c|c|c|c|}
\hline Sperm from & $\mathrm{Ea} \times \mathrm{Ea}$ & $\mathrm{Ea} \times \mathrm{Ec}$ & $\mathrm{Ec} \times \mathrm{Ea}$ & $\mathrm{Ec} \times \mathrm{Ec}$ \\
\hline $\mathrm{Ea} \times \mathrm{Ea}$ & $99.7 \pm 0.5(99-100)$ & $93.0 \pm 1.4(91-95)$ & $98.0 \pm 1.4(96-100)$ & $86.8 \pm 1.7(84-88)$ \\
\hline $\mathrm{Ea} \times \mathrm{Ec}$ & $84.0 \pm 1.6(82-86)$ & $99.0 \pm 0.9(98-100)$ & $95.0 \pm 1.4(93-97)$ & $99.3 \pm 0.8(98-100)$ \\
\hline $\mathrm{Ec} \times \mathrm{Ea}$ & $86.5 \pm 1.9(84-88)$ & $86.0 \pm 1.8(83-88)$ & $99.5 \pm 0.8(98-100)$ & $99.7 \pm 0.5(99-100)$ \\
\hline $\mathrm{Ec} \times \mathrm{Ec}$ & $30.7 \pm 2.0(28-33)$ & $82.2 \pm 1.8(80-84)$ & $89.2 \pm 2.1(87-93)$ & $99.8 \pm 0.4(99-100)$ \\
\hline
\end{tabular}

Each value represents six replicate crosses with gametes from different individuals in each replicate; mean $\pm \mathrm{SD}$, ranges in parentheses.

(Hinegardner, 1975; Levitan et al., 1991), and probably even less in tropical species. Asynchrony in spawning, therefore, would ensure that these two species could exist in sympatry as separate species whether or not their gametes are capable of fertilization (Lessios, 1984). However, Ea and Ec mature at the same time and their spawning periods overlap extensively (Arakaki and Uehara, 1991; Table 1). Consequently, seasonal separation of spawning is not a mechanism of reproductive isolation. On the other hand, gametes may be released at different times of the day or specific pheromonal spawning cues may differ between the species, and these factors may prevent near simultaneous spawning that could lead to hybridization. Natural spawning in the field has not yet been observed.

The sperm concentration used in this study was probably much higher than would be encountered under usual natural conditions, especially considering the dilution that would occur if individuals were separated by $1 \mathrm{~m}$ or more (Pennington, 1985; Levitan, 1998b). However, Uehara et al. (1990) provide data showing that fertilization rates of eggs of both Ea and Ec mixed with sperm from Ea were similar over a wide range of sperm concentrations, whereas the sperm of Ec had very low fertilization success with Ea eggs, even at high concentrations, up to $10^{-2}$. Consequently, it is equivocal whether inappropriate sperm concentrations were used in this study, and Ea sperm, at least, appear as likely to fertilize Ec eggs as Ea eggs over concentrations found in the field.

In addition, the eggs in this study were exposed to sperm at relatively high concentrations for $1.5 \mathrm{~h}$, much longer than they would likely be so exposed in the field. Levitan et al. (1991) found that fertilization increases in sea urchins with time of exposure of eggs to sperm over a range of $10-60 \mathrm{~s}$. It is possible, therefore, that fertilization rates would be lower in the Ec $\times$ Ea crosses if the gametes had been kept together for shorter times. Preliminary experiments indicate that fertilization reaches the asymptote in less than $2 \mathrm{~min}$ in conspecific crosses of $\mathrm{Ea}$ and $\mathrm{Ec}$, within $4 \mathrm{~min}$ in $\mathrm{Ec} \times \mathrm{Ea}$ crosses, and by about $6 \mathrm{~min}$ in Ea $\times$ Ec crosses (Rahman, unpubl. data). Therefore, more extended exposure times, like those used in the study, would not increase the fertilization rates. However, if gametes are spawned in the field at the same time by equal numbers of adjacent individuals of both sexes of both species, most conspecific gametes would probably be fertilized before much hybridization could occur. On the other hand, where the populations intermingle it seems as likely that a spawning Ec female could be closer to a spawning Ea male than to spawning Ec males, so that hybrids could be expected to occur.

To date there have been no experiments with mixed populations of gametes. Palumbi (1998) showed that at low concentrations where less than near $100 \%$ fertilization is achieved, sperm from different males of the same species of sea urchins fertilized different proportions of eggs from the same female, and eggs from different females were fertilized in different proportions by sperm from the same male. These differences were further related to differences in the sequence of the bindin alleles. This opens the possibility of some sort of interlocus antagonistic coevolution between gametes, as was proposed by Rice (1998) and which was demonstrated to be occurring in multiple-mating, internally fertilizing species such as crickets (Howard et al., 1998). How such sperm competition could be achieved in broadcast spawning, externally fertilizing species such as sea urchins, if it occurs at all, remains to be determined. However, if it does occur, and if conspecific sperm are always at an advantage when mixed at low concentrations with sperm from another species because of more compatible gametes, a mechanism for maintaining species integrity in sympatric species may be present.

Some characteristics of the hybrid progeny found in the present study were mainly maternal. Color patterns of both hybrids, for instance, tended to be maternally inherited. Maternal inheritance of color pattern also was observed in hybrids between Strongylocentrotus nudus and S. intermedius (Osanai 1974). On the other hand, other characteristics, such as spine length and spicule shapes, especially those from the gonads, showed intermediate features, and can be used to distinguish the hybrids from either parent. Such distinct hybrid phenotypes are important for finding hybrids 
in the field (e.g., Hagström and Lønning, 1961; Menge, 1986; Palumbi and Metz, 1991; Lessios and Pearse, 1996). We searched for distinctive intermediate phenotypes in the field, and although suggestive color morphs were found, examination of the spicules revealed no hybrids. Similarly, although hybrids with distinguishing characteristics can be formed in the laboratory between Ea and Ed, Aslan and Uehara (1997) were unable to find such hybrids in the field. Moreover, although two species of the tropical long-spined sea urchins, Diadama savignyi and D. setosum, readily hybridize in the laboratory (Uehara et al., 1990) and often occur in mixed populations in the field (Pearse, 1998), genetic analyses, using allozyme analyses, showed that hybrids only occur rarely in the field and there is limited introgression (Lessios and Pearse, 1996). Genetic analyses using allozyme or DNA markers should now be done with sympatric species of Echinometra to determine whether some introgression is occurring that has not been detectable by morphological characters.

The adult hybrids of these two species were completely fertile, indicating that genetic differences between them are not large enough to cause developmental or gamete incompatibility, in spite of their morphological differences and microhabitat segregation. The high fertilization rates in backcrossing further suggests that they are genetically very close to each other. Similar results were obtained from crosses that produced fertile hybrids between Ea and the putatively more distantly related Ed (Aslan and Uehara, 1997). There is no reason to believe that fertile hybrids could not be produced in crosses between most other species of Echinometra on Okinawa, including between Ec and Ed, which show high fertilization with each other in both directions (Uehara et al., 1990). Only Ea and Eb (=Echinometra mathaei) showed very low fertilization with each other in either direction, and may be isolated by gamete incompatibility (Uehara et al., 1990; Metz et al., 1994). These latter two species co-occur in pools and channels below mean low water on the reef flats of Okinawa, and they may have the greatest opportunity for gamete mixing in the field. Consequently, for these two species, gamete incompatibility may be necessary to maintain species integrity. Reproductive isolation of the other species, however, probably depends on additional prezygotic isolating mechanisms, such as microhabitat separation.

New biological species are formed when populations become reproductively isolated from other, previously conspecific populations. How and when reproductive isolation develops has yet to be established for broadcast spawning marine invertebrates such as sea urchins (Lessios, 1984; Knowlton, 1993; Palumbi, 1994). Although not isolated by full gamete incompatibility, or by hybrid inviability or infertility, Ea and Ec are both morphologically and genetically distinct, and hybridization between them appears to be either very low or nonexistent - that is, they appear to be effectively reproductively isolated. The morphological distinctness and apparent genetic integrity maintained between them warrants their recognition as distinct biological species despite their ability to produce viable and fertile hybrids in the laboratory. They should be given taxonomic descriptions and appropriate species names that are distinct from Echinometra mathaei, sensu stricto (=Eb; Arakaki et al., 1998) and Ed (=the Okinawan component of the Echinometra oblonga species complex; Arakaki and Uehara, 1999).

\section{Acknowledgments}

We are greatly indebted to L. M. Aslan, H. A. Lessios, H. Ota, and two anonymous reviewers for their critical and valuable suggestions on this manuscript. We also extend our appreciation and grateful thanks to the Director and staff of the Sesoko Station of the Tropical Biosphere Research Center, University of the Ryukyus, who provided space and facilities for culturing sea urchins; and to Motobu Fisheries Research Center for providing samples of Chaetoceros gracilis and instructions for culturing it. The first author is also grateful to the Rotary Yoneyama Memorial Foundation, Japan, for scholarship grants, and especially to Dr. Tomio Iha, Naha Rotary Club, Okinawa, for his continuous cooperation and encouragement during the period of the grants.

\section{Literature Cited}

Amy, R. L. 1983. Gamete sizes and developmental time tables of five tropical sea urchins. Bull. Mar. Sci. 33: 173-176.

Arakaki, Y. 1989. A comparative ecological and reproductive study on the four types of sea urchin Echinometra mathaei (Blainville) on Okinawan reef flats. Master's thesis, University of the Ryukyus, Japan.

Arakaki, Y., and T. Uehara. 1991. Physiological adaptation and reproduction of the four types of Echinometra mathaei (Blainville). Pp 105-111 in Biology of Echinodermata, T. Yanagisawa, I. Yasumasu, C. Oguro, N. Suzuki, and T. Motokawa, eds. A. A. Balkema, Rotterdam.

Arakaki, Y., and T. Uehara. 1999. Morphological comparison of black Echinometra individuals among those in the Indo-west Pacific. Zool. Sci. Japan 16: 551-558.

Arakaki, Y., T. Uehara, and I. Fagoone. 1998. Comparative studies of the genus Echinometra from Okinawa and Mauritius. Zool. Sci. (Tokyo) 15: $159-168$.

Aslan, L. M., and T. Uehara. 1997. Hybridization and $F_{1}$ backcrosses between two closely related tropical species of sea urchins (genus Echinometra) in Okinawa. Invertebr. Reprod. Dev. 31: 319-324.

Bartlett, M. S. 1937. Some examples of statistical methods of research in agriculture and applied biology. J. Roy. Stat. Soc., Suppl. 4: 137170.

Byrne, M., and M. J. Anderson. 1994. Hybridization of sympatric Patiriella species (Echinodermata: Asteroidea) in New South Wales Evolution 48: 564-576.

Chen, P. S., and F. Baltzer. 1975. Morphology and biochemistry of diploid and androgenetic haploid (merogonic hybrids). Pp. 424-445 in The Sea Urchin Embryo-Biochemistry and Morphogenesis, G. Czihak, ed. Springer-Verlag, Berlin.

Coyne, J. A. 1992. Genetics and speciation. Nature 355: 511-515,

Dobzhansky, T., F. J. Ayala, G. L. Stebbins, and J. W. Valentine. 1977. Evolution. W. H. Freeman, San Francisco. 
Duncan, D. B. 1955. Multiple range and multiple F-tests. Biometrics 11: $1-42$.

Hagström, B. E., and S. Lønning. 1961. Morphological and experimental studies on the genus Echinus. Sarsia 4: 21-31.

Hinegardner, R. 1975. Care and handling of sea urchin eggs, embryos, and adults (principally North American species). Pp. 10-25 in The Sea Urchin Embryo-Biochemistry and Morphogenesis, G. Czihak, ed. Springer-Verlag, Berlin.

Howard, D. J., M. Reece, P. G. Gregory, V. Chu, and M. L. Cain. 1998. The evolution of barriers to fertilization between closely related organisms. Pp. 279-288 in Endless Forms: Species and Speciation, D. J. Howard and S. H. Berlocher, eds. Oxford University Press, New York.

Knowlton, N. 1993. Sibling species in the sea. Annu. Rev. Ecol. Syst. 24: $189-216$.

Lessios, H. A. 1984. Possible prezygotic reproductive isolation in sea urchins separated by the Isthmus of Panama. Evolution 38: 1144-1148.

Lessios, H. A. 1998. The first stage of speciation as seen in organisms separated by the Isthmus of Panama. Pp. 186-201 in Endless Forms: Species and Speciation, D. J. Howard and S. H. Berlocher, eds. Oxford University Press, New York.

Lessios, H. A., and C. W. Cunningham. 1990. Gametic incompatibility between species of the sea urchin genus Echinometra on the two sides of the Isthmus of Panama. Evolution 44: 933-941.

Lessios, H. A., and J. S. Pearse. 1996. Hybridization and introgression between Indo-Pacific species of Diadema. Mar. Biol. 126: 715-723.

Levitan, D. 1998a. Does Bateman's principle apply to broadcast-spawning organisms? Egg traits influence in situ fertilization rates among congeneric sea urchins. Evolution 52: 1043-1056.

Levitan, D. R. 1998b. Sperm limitation, gamete competition, and sexual selection in external fertilizers. Pp. 175-217 in Sperm Competition and Sexual Selection, T. R. Birkhead and A. P. Møller, eds. Academic Press, San Diego, CA.

Levitan, D. R., M. A. Sewell, and F.-S. Chia. 1991. Kinetics of fertilization in the sea urchin Strongylocentrotus franciscanus: interaction of gamete dilution, age, and contact time. Biol. Bull. 181: 371-378.

Matsuoka, N., and T. Hatanaka. 1991. Molecular evidence for the existence of four sibling species within the sea urchin, Echinometra mathaei in Japanese waters and their evolutionary relationships. Zool. Sci. (Tokyo) 8: 121-133.

Mayr, E. 1970. Populations, Species, and Evolution. Harvard University Press, Cambridge, MA.

McCartney, M. A., G. Keller, and H. A. Lessios. 2000. Dispersal barriers in tropical oceans and speciation in Atlantic and eastern Pacific sea urchins of the genus Echinometra. Mol. Ecol. 9: 1391-1400.

Menge, B. A. 1986. A preliminary study of the reproductive ecology of the sea stars Asterias vulgaris and A. forbesi in New England. Bull. Mar. Sci. 39: 467-476.

Metz, E. C., and S. R. Palumbi. 1996. Positive selection and sequence rearrangements generate extensive polymorphism in the gamete recognition protein binding. Mol. Biol. Evol. 13: 397-406.

Metz, E. C., R. E. Kane, H. Yanagimachi, and S. R. Palumbi. 1994. Fertilization between closely related sea urchins is blocked by incompatibilities during sperm-egg attachment and early stages of fusion. Biol. Bull. 187: 23-34

Nishihira, M., Y. Sato, Y. Arakaki, and M. Tsuchiya. 1991. Ecological distribution and habitat preference of four types of Echinometra mathaei on Okinawan coral reef. Pp. 91-104 in Biology of Echinodermata, T. Yanagisawa, I. Yasumasu, C. Oguro, N. Suzuki, and T Motokawa, eds. A. A. Balkema, Rotterdam

Osanai, K. 1974. Interspecific hybridization of sea urchins, Strongylo- centrotus nudus and Strongylocentrotus intermedius. Bull. Mar. Biol. Stn. Asamushi 15: 37-45.

Palumbi, S. R. 1994. Genetic divergence, reproductive isolation, and marine speciation. Annu. Rev. Ecol. Syst. 25: 547-572.

Palumbi, S. R. 1996. What can molecular genetics contribute to marine biogeography? An urchin's tale. J. Exp. Mar. Biol. Ecol. 203: 75-92.

Palumbi, S. R. 1998. Species formation and the evolution of gamete recognition loci. Pp. 271-278 in Endless Forms: Species and Speciation, D. J. Howard and S. H. Berlocher, eds. Oxford University Press, New York.

Palumbi, S. R., and E. C. Metz. 1991. Strong reproductive isolation between closely related tropical sea urchins (genus Echinometra). Mol. Biol. Evol. 8: 227-239.

Palumbi, S. R., G. Grabowsky, T. Duda, L. Geyer, and N. Tachino. 1997. Speciation and population genetic structure in tropical Pacific sea urchins. Evolution 51: 1506-1517.

Pearse, J. S. 1998. Distribution of Diadema savignyi and D. setosum in the tropical Pacific. Pp. 777-782 in Echinoderms: San Francisco, R. Mooi and M. Telford, eds. A. A. Balkema, Rotterdam.

Pearse, J. S., and R. A. Cameron. 1991. Echinodermata: Echinoidea. Pp. 513-662 in Reproduction of Marine Invertebrates, Vol. VI, Echinoderms and Lophophorates, A. C. Giese, J. S. Pearse, and V. B. Pearse, eds. Boxwood Press, Pacific Grove, CA.

Pennington, J. T. 1985. The ecology of fertilization of echinoid eggs: the consequences of sperm dilution, adult aggregation, and synchronous spawning. Biol. Bull. 169: 417-430.

Rahman, M. A., and T. Uehara. 2001. Induction of metamorphosis and substratum preference in four sympatric and closely related species of sea urchins (Genus Echinometra) in Okinawa. Zool. Stud. 40: 29-43.

Rahman, M. A., T. Uehara, and L. M. Aslan. 2000. Comparative viability and growth of hybrids between two sympatric species of sea urchins (genus Echinometra) in Okinawa. Aquaculture 183: 45-56.

Rice, W. R. 1998. Intergenomic conflict, interlocus antagonistic coevolution, and the evolution of reproductive isolation. Pp. 261-270 in Endless Forms: Species and Speciation, D. J. Howard and S. H. Berlocher, eds. Oxford University Press, New York.

Tsuchiya, M., and M. Nishihira. 1984. Ecological distribution of two types of sea-urchin, Echinometra mathaei (Blainville). Galaxea 3: 131-143.

Tsuchiya, M., and M. Nishihira. 1985. Agonistic behavior and its effect on the distribution pattern in two types of the sea urchin Echinometra mathaei (Blainville). Galaxea 4: 37-48.

Uehara, T. 1990. Speciation in Echinometra mathaei. Iden 44: 47-53 (in Japanese).

Uehara, T., and M. Shingaki. 1985. Taxonomic studies in the four types of sea urchin, Echinometra mathaei from Okinawa. Zool. Sci. (Tokyo) 2: 1109

Uehara, T., H. Asakura, and Y. Arakaki. 1990. Fertilization blockage and hybridization among species of sea urchins. Pp. 305-310 in Advances in Invertebrate Reproduction, M. Hoshi and $\mathrm{O}$. Yamashita, eds. Elsevier, Amsterdam.

Uehara, T., M. Shingaki, K. Taira, Y. Arakaki, and H. Nakatomi. 1991. Chromosome studies in eleven Okinawan species of sea urchins, with special reference to four species of the Indo-Pacific Echinometra. Pp. 119-129 in Biology of Echinodermata, T. Yanagisawa, I. Yasumasu, C. Oguro, N. Suzuki, and T. Motokawa, eds., A. A. Balkema, Rotterdam.

Vacquier, V. D., W. J. Swanson, and M. E. Hellberg. 1995. What have we learned about sea urchin sperm binding? Dev. Growth Differ. 37: $1-10$. 

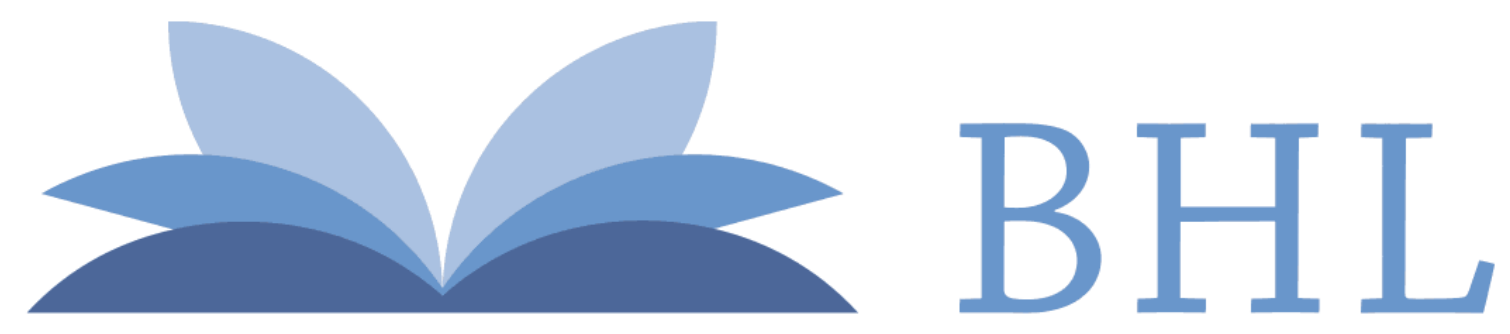

\section{Biodiversity Heritage Library}

Rahman, M Aminur, Uehara, Tsuyoshi, and Pearse, John S. 2001. "Hybrids of Two Closely Related Tropical Sea Urchins (Genus Echinometra): Evidence Against Postzygotic Isolating Mechanisms." The Biological bulletin 200, 97-106. https://doi.org/10.2307/1543303.

View This Item Online: https://www.biodiversitylibrary.org/item/17254

DOI: https://doi.org/10.2307/1543303

Permalink: https://www.biodiversitylibrary.org/partpdf/10999

\section{Holding Institution}

MBLWHOI Library

\section{Sponsored by}

MBLWHOI Library

\section{Copyright \& Reuse}

Copyright Status: In copyright. Digitized with the permission of the rights holder.

License: http://creativecommons.org/licenses/by-nc-sa/3.0/

Rights: https://biodiversitylibrary.org/permissions

This document was created from content at the Biodiversity Heritage Library, the world's largest open access digital library for biodiversity literature and archives. Visit BHL at https://www.biodiversitylibrary.org. 